\title{
GESTÃO DE ESTOQUE: O CONTROLE INTERNO NA GESTÃO DO ESTOQUE DE MICROEMPRESAS
}

\section{ARTIGO ORIGINAL}

SOUZA JUNIOR, Elielson Lima de ${ }^{1}$, MACHADO, Janderson Gomes², RODRIGUES, Keroleny Conceição de Araújo ${ }^{3}$, FREITAS, Ryan Phellipe Crisóstomo de ${ }^{4}$, ROBERTO, José Carlos Alves ${ }^{5}$, SERRA, Meg Rocha da Cunha ${ }^{6}$, LOPES, Nelânia Ferreira $^{7}$

SOUZA JUNIOR, Elielson Lima de. Et al. Gestão de estoque: o controle interno na gestão do estoque de microempresas. Revista Científica Multidisciplinar Núcleo do Conhecimento. Ano. 06, Ed. 11, Vol. 11, pp. 05-26. Novembro 2021. ISSN: 2448-0959, Link de acesso: https://www.nucleodoconhecimento.com.br/contabilidade/estoque-demicroempresas, DOI: 10.32749/nucleodoconhecimento.com.br/contabilidade/estoque-de-microempresas

\section{RESUMO}

O gerenciamento de estoque, enquanto a principal fonte de capital de giro, tem-se caracterizado como um dos principais pilares de uma microempresa bem-sucedida. Trabalhar com valores reais, quantidades disponíveis e controle adequado de entradas e saídas é a essência de uma excelente gestão de estoques. Assim, o questionamento levantado que norteou esta pesquisa foi o seguinte: Qual a

\footnotetext{
${ }^{1}$ Graduando do curso de Ciências Contábeis.

${ }^{2}$ Graduando do curso de Ciências Contábeis.

${ }^{3}$ Graduanda do curso de Ciências Contábeis.

${ }^{4}$ Graduando do curso de Ciências Contábeis.

${ }^{5}$ Orientador. Mestre em Engenharia de Produção. Especialista em Logística empresarial. Graduado em Administração com ênfase em Marketing.

${ }^{6}$ Orientadora. Mestra em Engenharia de Processos Industriais pela UFPA, especialista em Controladoria e Auditoria Contábil pelo Ciesa, Graduada em Ciências Contábeis pelo Centro Universitário do Norte. Graduada em Ciências Econômicas pelo Centro Universitário do Norte.

${ }^{7}$ Especialista em Auditoria Contábil, Financeira e Tributária e Graduada em Ciências Contábeis.
}

RC: 101776

Disponível em: https://www.nucleodoconhecimento.com.br/contabilidade/estoque-demicroempresas 
importância da gestão de estoques e quais são os procedimentos adequados para se alcançar uma gestão eficiente? Baseado no questionamento levantado, o objetivo deste estudo é verificar a importância de uma boa gestão de estoque no âmbito das microempresas, analisando métodos, critérios, técnicas e procedimentos existentes que auxiliam diretamente na execução do gerenciamento de estoques. Para atingir os objetivos, a metodologia de pesquisa empregada foi a bibliográfica, de natureza exploratória e descritiva. Logo, os resultados da pesquisa evidenciaram que a adoção de controle interno, aplicando alguns de seus princípios, contribuem diretamente para a eficiência das operações administrativas e operacionais de uma microempresa. A utilização de métodos e critérios adequados ao tipo de estoque influenciam diretamente nos resultados, colaborando diretamente com a geração de informações úteis e tempestivas, auxiliando na tomada de decisão pelos gestores. Cabe ressaltar que, a pesquisa evidenciou, ainda, a importância do estoque para uma microempresa, assim como o correto gerenciamento, utilizando-se de controles e procedimentos efetivos.

Palavras-chave: Microempresas, Controle interno, Gestão de estoque.

\section{INTRODUÇÃO}

O mercado tem se tornado cada vez mais versátil e dinâmico, fazendo com que os profissionais que atuam direta e indiretamente no ramo, assim como as empresas, tenham que aprimorar seus conhecimentos e se adaptar às mudanças continuamente, adotando novas estratégias competitivas para se manter no ritmo versátil imposto pelo mercado, mantendo-se lucrativos em suas atividades. No meio gerencial, diversas ferramentas podem ser adotadas para uma gestão eficiente, bem como diversos conceitos são discutidos pelos especialistas da área. Especificamente tratando-se dos estoques, a adoção de controles internos tem sido a principal ferramenta no gerenciamento do ativo mais importante das empresas.

O objetivo desta pesquisa é verificar a importância de uma boa gestão de estoque no âmbito das microempresas, analisando métodos, critérios, técnicas e 
procedimentos existentes que auxiliam diretamente na execução do gerenciamento de estoques. O tema abordado foi escolhido após análises feitas de maneira informal em algumas microempresas, levantando o seguinte questionamento: qual a importância da gestão de estoques e quais são os procedimentos adequados para se alcançar uma gestão eficiente?

A adoção de controles internos na gestão de estoque aumenta o nível da qualidade e da confiabilidade das informações contábeis. Esta acompanhada das técnicas e procedimentos de gestão de estoque, desde que corretamente empregados, pode contribuir diretamente para a redução das dificuldades enfrentadas pelas microempresas, visando a eficiência conjunta da área administrativa e operacional.

Com isso, como metodologia serão utilizadas as pesquisas bibliográfica, quantitativa, exploratória e descritiva, com o propósito de elucidar as questões levantadas relacionadas ao tema, demonstrar a relevância da veracidade da informação contábil relacionada ao estoque, e reafirmar conceitos trazendo posicionamentos mais atualizados.

\section{FUNDAMENTAÇÃO TEÓRICA}

Marconi e Lakatos (2017) afirmam que toda pesquisa deve conter premissas ou pressupostos teóricos para fundamentar a interpretação do pesquisador, onde o modelo teórico servirá de embasamento à interpretação do significado dos dados colhidos e levantados na pesquisa. Nesta seção, serão apresentados conceitos, princípios, métodos e normas que norteiam os assuntos abordados neste artigo. É importante destacar que as bases bibliográficas são abrangentes, onde diversos autores nos mostram o assunto de suas perspectivas, porém, seguindo sempre as normas vigentes e um raciocínio linear (constante e regular). A ideia central é abordar de maneira simples e objetiva, tratando de assuntos já discutidos em outras oportunidades, com o intuito de atualizar a base bibliográfica (se for o caso) e demonstrar como a teoria está sendo aplicada na prática, e como ela deveria ser 
aplicada de maneira eficiente, buscando um maior grau de confiabilidade dos gestores em suas ações de controle dentro da empresa.

\subsection{DEFINIÇÃO DE MICROEMPRESAS}

A Lei Complementar no 123, de 14 de dezembro de 2006, chamada de Lei Geral da Micro e Pequena Empresa, traz no seu art. 3o, que Microempresa é aquela que, devidamente registrada no Registro de Empresas Mercantis ou no Registro de Pessoas Jurídicas, conforme o caso, aufira, em cada ano-calendário, receita bruta igual a $R \$ 360.000,00$ (trezentos e sessenta mil reais) (BRASIL, 2006).

A lei Geral da Micro e Pequena Empresa contêm as normas específicas que regem e regulam o funcionamento de microempresas no país, que teve como um de seus objetivos a desburocratização no que diz respeito às microempresas, tornando mais simples os processos de abertura e gerenciamento dessas.

Chiavenato (2009), ao conceituar empresas pequenas, diz que são empresas que têm poucos funcionários, poucos recursos (capital) e pequenas instalações, como no caso das microempresas.

Segundo Torres (2021), microempresa (ME) é a personalidade jurídica não enquadrada como microempreendedor individual (MEI) que pode optar pelo sistema de tributação simplificada Simples Nacional, e possui algumas das seguintes características: contratação de 9 (nove) até 19 (dezenove) funcionários, dependendo da empresa; se enquadra no regime tributário do Lucro Real ou Presumido; e pode escolher entre as categorias de natureza jurídica Sociedade Simples, Empresa Individual de Responsabilidade Limitada (EIRELI), Sociedade Empresária e Empresário Individual.

Outra característica de uma microempresa é ter, em seu rol de atividades exercidas descritas no CNAE (Classificação Nacional de Atividades Econômicas), nenhuma atividade enquadrada como atividade de Microempreendedor Individual. Cabe ressaltar que uma microempresa pode emitir notas fiscais para todos os tipos de 
vendas, para pessoas jurídicas ou pessoas físicas. Os impostos pagos pela microempresa vão depender do regime tributário adotado e da sua atividade exercida.

\subsection{CONCEITOS E OBJETIVOS DA CONTABILIDADE GERENCIAL}

A contabilidade gerencial, segundo ludícibus (2010), está voltada de maneira única e exclusiva para a administração de empresas, com o objetivo de suprir informações adequadamente válidas e efetivas no modelo decisório do administrador. O autor ainda afirma que todo procedimento, técnica, informação ou relatório contábil confeccionado adequadamente para a administração utilizar na tomada de decisão ou na avaliação de desempenho, recai na contabilidade gerencial.

Alves (2013) diz que a contabilidade gerencial tem suas raízes na contabilidade de custos, e, ao longo dos anos, se desenvolveu ao ponto de se tornar a principal finalidade da gestão de custos.

Para Padoveze (2012), a contabilidade gerencial incorpora todos os ramos da contabilidade e complementa a contabilidade financeira, tornando-a útil a informação contábil. Padoveze (2012) ainda destaca que o objetivo da contabilidade gerencial é auxiliar, com informação contábil útil e tempestiva (Princípio da Oportunidade), todas as ramificações das gestões das entidades.

Carraro et al (2018) afirmam que a contabilidade gerencial é usada para acompanhar os orçamentos, os processos, os resultados, os diagnósticos e os sistemas da empresa, a fim de promover feedback (retorno) e feedforward (projeção). Os autores afirmam ainda que a contabilidade gerencial objetiva auxiliar a gestão promovendo informações importantes para a tomada de decisões relacionadas à alocação de recursos, revisão de posicionamento estratégico e levantamento de custos. 


\subsection{CONTROLE INTERNO}

Os controles internos possuem um importante papel na resguarda dos ativos das empresas, permitindo que sejam descobertos e evitados erros e fraudes que culminem em prováveis prejuízos. É uma função administrativa que tem por objetivo medir e corrigir o desempenho, assegurando a realização das metas e objetivos da empresa, quando aplicada com eficiência (CHIAVENATO, 2014). A respeito disso, Nascimento e Reginato (2009) dizem que a falta ou ineficiência dos controles internos pode levar os gestores a tomarem decisões inadequadas, causando, em muitos casos, prejuízo para a empresa. Numa visão geral, é uma ferramenta importante para o desenvolvimento saudável de qualquer negócio.

Ribeiro e Coelho (2013) definem controle interno como o processo planejado, implementado e praticado pela governança, administração e outros funcionários, com o objetivo de fornecer segurança na execução dos objetivos das entidades relacionados não somente à credibilidade dos relatórios financeiros, mas também à efetividade e eficiência das operações, de acordo com as leis e regulamentos vigentes.

Segundo Crepaldi (2009), o controle interno compreende, além do plano organizacional, a inclusão de métodos que são utilizados pela empresa para proteger seus ativos, verificar a fidelidade de seus dados e informações contábeis, promover a eficiência operacional e direcionar a adesão à política traçada pela administração. A fidedignidade das informações e dos dados contábeis promovem a eficiência das atividades operacionais e administrativas da entidade, sendo o controle interno vital para o desempenho e desenvolvimento de quaisquer atividades exercidas.

A utilização adequada de um controle interno é fundamental para a entidade que visa obter resultados favoráveis, diminuindo ou até mesmo evitando prejuízos. É um processo de natureza estruturada que gera informações para os gestores, auxiliando-os na empreitada de fazer com que a entidade alcance seus objetivos, 
fornecendo principalmente relatórios e análises que reflitam a real e atual situação da entidade. Luz (2015) afirma que o controle interno produzirá dados contábeis com um grau maior de confiabilidade, e auxiliará a administração através de procedimentos, rotinas e métodos aplicados dentro da entidade.

\subsubsection{TIPOS DE CONTROLE INTERNO}

Os controles internos podem ser divididos em dois grupos: contábeis e administrativos. Os contábeis estão ligados diretamente às informações contábeis, especificamente os registros. Tem como objetivo assegurar a confiabilidade dos registros realizados (atos e fatos), principalmente os responsáveis por alterações no patrimônio da empresa. Os administrativos estão ligados diretamente com a área organizacional da entidade, especificamente relacionados ao cumprimento das normas internas definidas pelos gestores (ATTIE, 2011).

Vaassen et al. (2013) trouxeram o entendimento de que os controles internos podem ser classificados em: controles preventivos, controles investigativos e controles corretivos. Floriano (apud SANTOS e TRINDADE, 2010) também aborda os tipos de controle interno de maneira similar, dividindo-os em: preventivo, detectiva e corretiva. O controle preventivo atua como forma de prevenir o problema, servindo como guia na execução dos processos. Detectiva atua na deteç̧ão de problemas, permitindo a atuação tempestiva dos gestores na correção. Corretiva atua após a detecção de problemas nos processos, servindo como base para detectar outros possíveis erros.

Conforme William (2011), outros dois métodos de controles se sobressaem e ganham notoriedade por suas eficiências, são eles: controles contábeis e controles administrativos. Controles contábeis são procedimentos cujo objetivo é a salvaguarda do patrimônio e a veracidade dos registros contábeis. Controles administrativos são os métodos que abrangem o plano organizacional e os procedimentos relacionados à eficiência operacional e todas as decisões políticas da administração. 
Segundo Loureiro (2010 apud ALMEIDA, 2003), o controle interno compreende dois tipos de controles que podem ser adotados pela administração de uma empresa com a finalidade de salvaguardar seus ativos, produzir informações contábeis confiáveis e auxiliar na condução dos negócios, sendo eles: controles administrativos e controles contábeis. Loureiro (2010 apud ATTIE, 1985) discorre ainda sobre 0 entendimento desses dois tipos de controle: os controles administrativos envolvem o plano organizacional e os procedimentos de preservação do patrimônio, e os controles contábeis compreendem o plano organizacional e os procedimentos ligados diretamente com a eficiência das atividades operacionais. Nesse contexto, Silva (2013) afirma que, segundo a ENA 29 - Exposição de Normas de Auditoria no 29, os controles internos de uma empresa dividem-se em dois grupos: os de natureza administrativa e natureza contábil.

\subsubsection{PRINCÍPIOS DO CONTROLE INTERNO}

Gil et al. (2013) dizem que os princípios do controle interno contêm premissas e parâmetros intrínsecos aos sistemas de aplicação para suportar o modelo de gestão do ciclo de negócio de uma entidade. Já Blumen (2015) trata os princípios de controle interno como um guia para gestores de como implantar um sistema consistente de controle interno, levando em consideração fatores relevantes e críticos.

Amplo são os posicionamentos de profissionais da área quando se trata dos princípios do controle interno. Cabe ressaltar que, apesar de amplo os conceitos e posicionamentos, o raciocínio mantém-se linear. Dentre os princípios do controle interno, destaca-se:

a) segregação de funções

A segregação de funções compreende a correta divisão de tarefas dentro da entidade, evitando que um mesmo procedimento administrativo seja executado pelo mesmo agente. Castro (2014) afirma que este princípio aparece no bojo da atividade 
de controle como a orientação de que as funções administrativas sejam segregadas, ou seja, parceladas, entre vários agentes distintos.

b) Qualificação profissional e rodízio de funcionários (controladores)

Os profissionais que atuam em frentes administrativas necessitam ter o conhecimento mínimo desejável para que desenvolvam suas atividades de acordo com o cargo ocupado, sendo que todos devem receber treinamentos e qualificações adequadas para as suas funções. O rodízio desses profissionais visa precaver a correção de irregularidades e erros, muitas vezes causados pelo "vício da função". Além disso, o rodízio de funcionário proporciona a disseminação de conhecimento, evitando que as entidades fiquem refém de um único funcionário conhecedor de determinados assuntos.

c) Relação Custo versus benefício

O custo do controle não pode ser superior ao custo da atividade controlada. Os agentes controladores devem prezar pela otimização do uso de todo e qualquer recurso.

d) Aderência às Diretrizes e Normas

Agentes do controle interno devem se balizar pelas legislações vigentes, normas, manuais e regras preestabelecidas, sendo que todos os procedimentos do controle interno devem ser justificáveis.

e) Controle sobre as transações

Os registros das transações contábeis só têm finalidades quando representam fielmente o fenômeno econômico, a situação patrimonial e financeira da entidade. Devem ser acompanhados de perto esperando-se constatar a legalidade, a legitimidade e a concordância dos atos com a finalidade no uso dos recursos.

f) Procedimentos documentados

RC: 101776

Disponível em: https://www.nucleodoconhecimento.com.br/contabilidade/estoque-demicroempresas 
Todos os processos devem ser documentados de forma física ou eletrônica, tendo seu embasamento legal nas legislações vigentes. Isso possibilitará a verificação de todos os procedimentos.

\subsection{GESTÃO DE ESTOQUE}

$\mathrm{Na}$ gestão de estoques diversas ações são utilizadas pelos gestores para verificarem se estes estão sendo utilizados de maneira adequada e se estão bem alocados em relação às suas áreas de aplicação, com o manuseio e controle de acordo com as normas vigentes e políticas internas da entidade. Cabe ressaltar que, de acordo com Beckedorff e Garcia (2007), a gestão de estoque deve ser analisada também sob a visão estratégica da entidade, e não somente pela compreensão de enfoque operacional.

Para Ching (2011), gestão de estoque não é apenas um método de redução de custos, mas sim uma ferramenta de estratégia fundamental para uma empresa.

Graziani (2013), quando trata do objetivo, afirma que a gestão de estoque equilibra a necessidade de disponibilidade de produtos com os custos de abastecimento em razão do nível de determinado estoque.

Novaes (2010) destaca que é da administração de materiais que se originam quase todas as decisões, metas e ações do processo produtivo de uma empresa, sendo necessário uma eficiente administração de estoque, recursos humanos e informações sobre as necessidades dos clientes.

\subsubsection{CONCEITO DE ESTOQUE}

O conceito de estoque, de acordo com Gelbcke (2018), são bens tangíveis ou intangíveis adquiridos ou produzidos pela empresa com o objetivo de venda ou utilização própria no curso normal de suas atividades. Fleury e Figueiredo (2006) afirmam que os estoques representam o capital investido, lançado no ativo da empresa para serem administrados e vendidos.

RC: 101776

Disponível em: https://www.nucleodoconhecimento.com.br/contabilidade/estoque-demicroempresas 
O CPC (2009) diz que estoques são: ativos mantidos para venda nas atividades rotineiras da empresa, ou em processo de fabricação visando a comercialização, ou na forma de matérias-primas que serão consumidas e transformadas no processo de produção ou materiais utilizados na prestação de serviços.

Sabe-se que todas as entidades, independentemente de seu porte, possuem um estoque, seja ele para comercialização ou para uso da própria empresa em suas atividades administrativas, normalmente ligados às principais áreas de operações. Esses estoques, independentemente de sua finalidade, envolvem problemas de administração e controle e de contabilização e avaliação (mensuração). O gerenciamento de estoques requer recursos para sua mobilização, movimentação e armazenagem.

\subsubsection{MÉTODOS DE CONTROLE DE ESTOQUE}

Ribeiro (2013) diz que, durante um exercício social, a empresa faz a aquisição de várias unidades de um mesmo tipo de mercadoria de valores diversos, sendo necessário a adoção de métodos voltados à mensuração do custo dessas mercadorias que estão no estoque, assim como as que foram comercializadas. Nesse contexto, o autor destaca os mais conhecidos métodos para avaliação e mensuração de estoques, dentre eles o PEPS, UEPS e Custo Médio.

\subsubsection{PEPS}

No PEPS, os itens do estoque são identificados pela data de recebimento, e os itens que entram primeiro devem sair antes dos itens que entraram posteriormente. Dias (2010) afirma que a avaliação por este método é realizada pela ordem cronológica das entradas. Ribeiro (2009) diz que na adoção do critério PEPS para valoração dos estoques, a empresa irá atribuir às mercadorias armazenadas os custos mais recentes. 
Schier (2011) destaca que no método PEPS, a baixa do estoque é realizada pelo custo mais antigo, obedecendo a ordem cronológica das entradas. $O$ autor destaca ainda, que esse método é o aceito pelo fisco, pois proporciona arrecadação adequada sobre a visão tributária, já que os valores apresentados são os mais próximos da realidade.

Vejamos um exemplo:

Fatos ocorridos:

1. Em 10/03, adquiriu do fornecedor Só Portas Ltda 150 unidades de portas por $\mathrm{R} \$ 100,00$ cada, conforme NF no 885 ;

2. Em 12/03, vendeu ao cliente Depósito Timbira Ltda. 50 unidades de portas, conforme NF no 57;

3. Em 17/03, adquiriu do fornecedor Só Portas Ltda, 75 unidades de portas por $\mathrm{R} \$ 125,00$ cada, conforme NF № 972;

4. Em 21/03, adquiriu do fornecedor Só Portas Ltda, 75 unidades de portas por $\mathrm{R} \$ 145,00$ cada, conforme NF no 1.023 ;

5. Em 31/03, vendeu ao cliente Tupinambá S/A 120 unidades de portas, conforme NF no 58;

6. Em 07/04, recebeu uma devolução do cliente Tupinambá S/A 5 unidades de porta, conforme NFE no 27; essas portas integram o lote de 120 unidades de portas vendidas ao mesmo cliente conforme NF 058 . 
Tabela 01 - Ficha de Controle de Estoques PEPS

\begin{tabular}{|c|c|c|c|c|c|c|c|c|c|c|}
\hline \multicolumn{11}{|c|}{$\begin{array}{l}\text { Mercadoria: Portas de madeira } \\
\text { Método de Controle: PEPS }\end{array}$} \\
\hline \multirow[t]{2}{*}{ Data } & \multirow[t]{2}{*}{ Histórico } & \multicolumn{3}{|c|}{ Entradas } & \multicolumn{3}{|c|}{ Saídas } & \multicolumn{3}{|c|}{ Saldo } \\
\hline & & Quant & $\begin{array}{l}\text { Custo } \\
\text { Unit }\end{array}$ & $\begin{array}{l}\text { Custo } \\
\text { Total }\end{array}$ & Quant & $\begin{array}{l}\text { Custo } \\
\text { Unit }\end{array}$ & $\begin{array}{l}\text { Custo } \\
\text { Total }\end{array}$ & Quant & $\begin{array}{l}\text { Custo } \\
\text { Unit }\end{array}$ & $\begin{array}{l}\text { Custo } \\
\text { Total }\end{array}$ \\
\hline $10 / 03$ & NF n ${ }^{\circ} 885$ & 150 & 100 & 15.000 & - & - & - & 150 & 100 & 15.000 \\
\hline $12 / 03$ & $N F n^{0} 57$ & - & - & - & 50 & 100 & 5.000 & 100 & 100 & 10.000 \\
\hline $17 / 03$ & NF n ${ }^{\circ} 972$ & 75 & 125 & 9.375 & - & - & - & $\begin{array}{l}{\left[\begin{array}{l}100 \\
75\end{array}\right.} \\
=175\end{array}$ & $\begin{array}{l}100 \\
125\end{array}$ & $\begin{array}{l}{\left[\begin{array}{l}10.000 \\
9.375\end{array}\right.} \\
=19.375\end{array}$ \\
\hline $21 / 03$ & $\begin{array}{l}\mathrm{NF} \mathrm{n}^{\circ} \\
1.023\end{array}$ & 75 & 145 & 10.875 & - & - & - & $\begin{array}{l}\left\{\begin{array}{l}100 \\
75 \\
75\end{array}\right. \\
=250\end{array}$ & $\begin{array}{l}100 \\
125 \\
145\end{array}$ & $\begin{array}{c}10.000 \\
9.375 \\
10.875 \\
=30.250\end{array}$ \\
\hline $31 / 03$ & $N F n^{0} 58$ & - & - & - & $\begin{array}{l}\left\{\begin{array}{l}100 \\
20\end{array}\right. \\
=120\end{array}$ & $\begin{array}{l}100 \\
125\end{array}$ & $\begin{array}{c}{\left[\begin{array}{l}10.000 \\
2.500\end{array}\right.} \\
= \\
12.500\end{array}$ & $\begin{array}{l}\left\{\begin{array}{l}55 \\
75\end{array}\right. \\
=120\end{array}$ & $\begin{array}{l}125 \\
145\end{array}$ & $\begin{array}{l}\left\{\begin{array}{c}6.875 \\
10.875\end{array}\right. \\
=17.750\end{array}$ \\
\hline $07 / 04$ & NFE $n^{\circ} 27$ & - & - & - & (5) & 125 & (625) & $\begin{array}{l}\left\{\begin{array}{l}60 \\
75\end{array}\right. \\
=125\end{array}$ & $\begin{array}{l}125 \\
145\end{array}$ & $\begin{array}{l}\left\{\begin{array}{l}7.500 \\
10.875\end{array}\right. \\
=18.375\end{array}$ \\
\hline & OTAIS & 300 & - & 35.250 & 165 & - & 16.875 & - & - & 18.375 \\
\hline
\end{tabular}

Fonte: Adaptado de Ribeiro (2013, p.200)

\subsubsection{UEPS}

O método UEPS propõe o contrário, onde os produtos que entraram mais recentemente no estoque devem ser os primeiros a sair. Dias (2010) diz que esse método considera que devem sair as últimas peças que primeiro deram entrada no estoque. Pinto et al (2017) descreve o método UEPS como um dos mais eficientes no planejamento da produção, permitindo ajustes eficazes nos valores e na quantidade de produtos a serem produzidos de acordo com a demanda real. Ribeiro 
(2009) afirma que na adoção deste método para valoração dos estoques, a empresa irá sempre atribuir às suas mercadorias armazenadas os custos mais antigos.

Segundo Marion (2015), esse critério traz os valores do estoque próximo ao custo de aquisição, atendendo o princípio do conservadorismo, contudo, é considerado ilegal conforme a legislação brasileira. Warren et al (2009), afirmam que este método não é aceito pois, num regime econômico onde há inflação, a tendência é de que os estoques fiquem subavaliados, diminuindo o lucro líquido do período e, consequentemente, os valores dos tributos arrecadados (IR e CSSL).

Segue um exemplo baseado nos mesmos fatos apresentados no item anterior, desta vez registrados na Ficha de Controle de Estoque pelo método UEPS:

Tabela 02 - Ficha de Controle de Estoques UEPS

\begin{tabular}{|c|c|c|c|c|c|c|c|c|c|c|}
\hline \multicolumn{11}{|c|}{$\begin{array}{l}\text { Mercadoria: Portas de madeira } \\
\text { Método de Controle: UEPS }\end{array}$} \\
\hline \multirow[t]{2}{*}{ Data } & \multirow[t]{2}{*}{ Histórico } & \multicolumn{3}{|c|}{ Entradas } & \multicolumn{3}{|c|}{ Saidas } & \multicolumn{3}{|c|}{ Saldo } \\
\hline & & Quant & $\begin{array}{l}\text { Custo } \\
\text { Unit }\end{array}$ & $\begin{array}{l}\text { Custo } \\
\text { Total }\end{array}$ & Quant & $\begin{array}{l}\text { Custo } \\
\text { Unit }\end{array}$ & $\begin{array}{l}\text { Custo } \\
\text { Total }\end{array}$ & Quant & $\begin{array}{l}\text { Custo } \\
\text { Unit }\end{array}$ & $\begin{array}{l}\text { Custo } \\
\text { Total }\end{array}$ \\
\hline 10/03 & NF no 885 & 150 & 100 & 15.000 & - & - & - & 150 & 100 & 15.000 \\
\hline $12 / 03$ & $N F n^{\circ} 57$ & - & - & - & 50 & 100 & 5.000 & 100 & 100 & 10.000 \\
\hline $17 / 03$ & $N F n^{\circ} 972$ & 75 & 125 & 9.375 & - & - & - & $\begin{array}{l}{\left[\begin{array}{l}100 \\
75\end{array}\right.} \\
=175\end{array}$ & $\begin{array}{l}100 \\
125\end{array}$ & $\begin{array}{l}{\left[\begin{array}{l}10.000 \\
9.375\end{array}\right.} \\
=19.375\end{array}$ \\
\hline $21 / 03$ & $\begin{array}{l}\mathrm{NF} \mathrm{n}^{\circ} \\
1.023\end{array}$ & 75 & 145 & 10.875 & - & - & - & $\begin{array}{l}\left\{\begin{array}{l}100 \\
75 \\
75\end{array}\right. \\
=250\end{array}$ & $\begin{array}{l}100 \\
125 \\
145\end{array}$ & $\begin{array}{l}{\left[\begin{array}{c}10.000 \\
9.375 \\
10.875\end{array}\right.} \\
=30.250\end{array}$ \\
\hline $31 / 03$ & $N F n^{\circ} 58$ & - & - & - & $\begin{array}{l}{\left[\begin{array}{l}75 \\
45\end{array}\right.} \\
=120\end{array}$ & $\begin{array}{l}145 \\
125\end{array}$ & $\begin{array}{l}{\left[\begin{array}{l}10.875 \\
5.625\end{array}\right.} \\
=16.500\end{array}$ & $\begin{array}{c}100 \\
30\end{array}$ & $\begin{array}{l}100 \\
125\end{array}$ & $\begin{array}{l}{\left[\begin{array}{l}10.000 \\
3.750\end{array}\right.} \\
=13.750\end{array}$ \\
\hline $07 / 04$ & NFE $n^{\circ} 27$ & - & - & - & (5) & 125 & (625) & $\begin{array}{c}100 \\
35\end{array}$ & $\begin{array}{l}100 \\
125\end{array}$ & $\begin{array}{l}{\left[\begin{array}{l}10.000 \\
4.375\end{array}\right.} \\
=14.375\end{array}$ \\
\hline & DTAIS & 300 & - & 35.250 & 165 & - & 20.875 & - & - & 14.375 \\
\hline
\end{tabular}

Fonte: Adaptado de Ribeiro (2013, p.201)

RC: 101776

Disponível em: https://www.nucleodoconhecimento.com.br/contabilidade/estoque-demicroempresas 


\subsubsection{CUSTO MÉDIO}

Também chamado de média ponderada móvel, este método avalia o valor do estoque cada vez que um novo produto é adicionado. É considerado o valor dos produtos antigos e novos, dividindo o total pela quantidade de itens no estoque.

Ribeiro (2009) divide este método em custo médio ponderado móvel e custo médio ponderado fixo. No custo médio ponderado móvel, as mercadorias estocadas sempre serão valorizadas pela média do custo de aquisição, atualizando a cada compra realizada, onde o custo unitário da aquisição é diferente do custo unitário do que consta no estoque. No custo médio ponderado fixo, o estoque é precificado uma única vez, no final do período, após realização da última compra. Ribeiro (2009) ainda afirma que este método só poderá ser implementado em entidades que empregam o sistema de inventário periódico, em que o custo médio obtido é cominado as unidades de itens disponíveis no estoque no dia da apuração, bem como a todas as mercadorias comercializadas durante o exercício social.

Vejamos os mesmos fatos já apresentados anteriormente, registrados na Ficha de Controle de Estoques pelo método do Custo Médio: 
Tabela 03 - Ficha de Controle de Estoques Custo Médio

\begin{tabular}{|c|c|c|c|c|c|c|c|c|c|c|}
\hline \multicolumn{11}{|c|}{$\begin{array}{l}\text { Mercadoria: Portas de madeira } \\
\text { Método de Controle: Custo Médio }\end{array}$} \\
\hline \multirow[t]{2}{*}{ Data } & \multirow[t]{2}{*}{ Histórico } & \multicolumn{3}{|c|}{ Entradas } & \multicolumn{3}{|c|}{ Saídas } & \multicolumn{3}{|c|}{ Saldo } \\
\hline & & Quant & $\begin{array}{l}\text { Custo } \\
\text { Unit }\end{array}$ & $\begin{array}{l}\text { Custo } \\
\text { Total }\end{array}$ & Quant & $\begin{array}{l}\text { Custo } \\
\text { Unit }\end{array}$ & $\begin{array}{l}\text { Custo } \\
\text { Total }\end{array}$ & Quant & $\begin{array}{l}\text { Custo } \\
\text { Unit }\end{array}$ & $\begin{array}{l}\text { Custo } \\
\text { Total }\end{array}$ \\
\hline $10 / 03$ & NF n ${ }^{\circ} 885$ & 150 & 100 & 15.000 & - & - & - & 150 & 100 & 15.000 \\
\hline $12 / 03$ & $\mathrm{NF} \mathrm{n}^{0} 57$ & - & - & - & 50 & 100 & 5.000 & 100 & 100 & 10.000 \\
\hline $17 / 03$ & $\mathrm{NF} \mathrm{n}^{\circ} 972$ & 75 & 125 & 9.375 & - & - & - & 175 & 110,71 & 19.375 \\
\hline $21 / 03$ & $\begin{array}{l}\mathrm{NF} \mathrm{n}^{\circ} \\
1.023\end{array}$ & 75 & 145 & 10.875 & - & - & - & 250 & 121 & 30.250 \\
\hline $31 / 03$ & $N F n^{0} 58$ & - & - & - & 120 & 121 & 14.520 & 130 & 121 & 15.730 \\
\hline $07 / 04$ & NFE $n^{0} 27$ & - & - & - & (5) & 121 & (605) & 125 & 121 & 16.335 \\
\hline & DTAIS & 300 & - & 35.250 & 165 & - & 18.915 & - & - & 16.335 \\
\hline
\end{tabular}

Fonte: Adaptado de Ribeiro (2013, p.202)

\subsection{IMPORTÂNCIA DO CONTROLE DE ESTOQUES NAS MICROEMPRESAS}

Em uma pesquisa realizada por Pinto et al. (2017) com o objetivo de analisar a importância da gestão de estoque para micro e pequenas empresa no ramo de varejo da construção civil, em uma cidade do interior do Rio de Janeiro, os autores inferiram que, embora $87 \%$ das empresas investigadas realizem controle de estoque, a maior parte o realizam de forma precária, dentre os quais $37 \%$ o fazem de forma visual, $25 \%$ através de planilha eletrônica, $12 \%$ por meio de planilha manual e $13 \%$ através de um sistema gerencial; ao passo que $13 \%$ não realizam nenhuma espécie de controle, atendendo a demanda de mercado de forma informal. Desta forma, em relação à concepção dos gestores, somente $12 \%$ deles têm a noção da importância da gestão de estoque para a dinâmica de sua empresa no mercado, enquanto a grande maioria acredita que uma micro e pequena empresa não necessita investir em instrumento de gestão de estoque, pois a movimentação de materiais é pequena e a implantação de ferramentas de gestão de estoque implica em custo.

RC: 101776

Disponível em: https://www.nucleodoconhecimento.com.br/contabilidade/estoque-demicroempresas 
Este cenário permite compreender que boa parte dos gestores de micro e pequenas empresas ainda estão apoiados em um processo de gestão praticamente amador, no qual consideram o investimento em instrumentos de gestão custos desnecessários e dispendiosos.

No entanto, de acordo com a concepção de Martins e Alt (2010), controle de estoque tem a capacidade de dinamizar a realidade de uma empresa no mercado com: redução de perdas, como exemplo, perda de produtos em virtude de vencimento; redução de custos decorrente de manutenção de estoque, funcionários, dentre outros; redução de capital ocioso, pois o recurso investido pode ficar parado; e redução da insatisfação do consumidor, pois a ausência de um produto pode implicar na migração do consumidor para a concorrência.

Martins e Alt (2009) afirmam que os estoques têm papel fundamental nas empresas, funcionando como reguladores do fluxo dos negócios. Os autores enfatizam que a necessidade de reposição dos estoques está diretamente relacionada com fluxo de entrada e saídas de itens: quanto maior o fluxo de saídas, maior será a necessidade de reposição, e vice-versa.

\subsubsection{TÉCNICAS E PROCEDIMENTOS PARA O CONTROLE DE ESTOQUES}

Diversas são as formas de controle de estoque, desde os critérios, como foram supracitados alguns deles, até as técnicas e procedimentos que podem ser empregados em uma microempresa visando a eficiência na gestão de seu estoque. $\mathrm{Na}$ adoção de técnicas, a empresa deve analisar a que melhor se enquadra no seu ramo de atividade, e a que mais traz resultados positivos no quesito custo-benefício, assim como a satisfação do cliente em sempre poder atendê-lo de acordo com a demanda desejada.

\section{Inventários}


Dentre os procedimentos utilizados, o inventário, ou balanço como é conhecido na linguagem comercial, é um dos adotados dentro das empresas. Inventário, segundo Castiglioni (2011, apud GRAZIANI, 2013, p. 40) é a contagem da quantidade de itens existentes num estoque para comparação com a contabilidade, tendo como objetivos: redução de perdas, com o aumento do controle dos produtos; atualização constante dos bancos de dados; garantia da integridade das informações, descobrindo possíveis erros; e otimização dos níveis de estoque. Os inventários podem ser divididos em Inventários Periódicos (ou Gerais) e em Inventários Rotativos.

Dias (2010) diz que inventários gerais são realizados uma só vez durante o exercício social, abrangendo todos os itens do estoque. Porém, sobre este método, o autor alerta para as falhas decorrentes dele: por ser uma operação de duração prolongada e incluir altas quantidades de itens, analisar as causas de divergências e ajustes em profundidade ficam impossibilitadas.

Sobre os inventários rotativos, Dias (2010) diz que as contagens dos estoques são programadas e distribuídas durante o exercício social, dividindo-as em 3 (três) grupos: grupo 1, itens mais significativos e inventariados três vezes ao exercício social; grupo 2, itens de importância intermediária, inventariados duas vezes ao exercício social; e grupo 3 , formado pelos demais itens de pequeno valor, inventariados uma vez ao exercício social.

\section{Giro de estoques}

Outro procedimento adotado para controle e gestão de estoque é o Giro de estoques. Graziani (2013) demonstra este procedimento através da razão entre as vendas anuais a custo de estoque e o investimento médio em estoque, considerando o mesmo período de venda:

O autor destaca ainda que, com este método é calculado a frequência que um estoque é utilizado em um determinado período: se o giro de estoques estiver alto, 
os produtos estão ficando pouco tempo armazenados, o que significa a redução de investimentos em capital de giro para determinados níveis de vendas.

\section{MATERIAIS E MÉTODOS}

\subsection{PROCEDIMENTOS METODOLÓGICOS}

Os procedimentos metodológicos para o desenvolvimento deste artigo, que serão apresentados em seguida, visam atender aos questionamentos levantados com um estudo amplo da problematização abordada, com o intuito de esclarecer conceitos e métodos adotados relacionados ao assunto em questão. Para Pereira (2018), o método científico é um trabalho sistemático, que tem como objetivo a busca de respostas às questões estudadas, é o caminho que se deve seguir para levar à formulação de uma teoria científica.

\subsection{QUANTO À NATUREZA: QUANTITATIVA}

De acordo com Zanella (2013), a pesquisa quantitativa é aquela que se caracteriza pelo emprego de instrumentos estatísticos na coleta e no tratamento dos dados, tendo como finalidade medir relações entre as variáveis, partindo de um plano preestabelecido com hipóteses e variáveis claramente definidas, medindo e quantificando os resultados da investigação, elaborando-os em dados estatísticos.

A empregabilidade desta abordagem, neste artigo, é a mais adequada, pois, tendo o conhecimento que esta utiliza-se de coleta e análise de dados visando o alcance de resultados, sabe-se que os dados serão necessários para o desenvolvimento do tema, e de que só é possível compreender a realidade com base na análise de dados coletados através de métodos de pesquisas. No contexto deste artigo, a coleta e análise de dados foi delimitada a um exemplo individual (pesquisa de campo). 


\subsection{QUANTOS AOS FINS: EXPLORATÓRIA E DESCRITIVA}

Severino (2007) afirma que a pesquisa exploratória busca apenas levantar informações sobre um determinado objeto, delimitando assim um campo de trabalho, mapeando as condições de manifestação desse objeto. Segundo Gil (2007, apud ZANELLA, 2013, p. 33), a pesquisa exploratória tem por finalidade a ampliação do conhecimento a respeito de um determinado fenômeno, explorando a realidade e buscando ainda mais conhecimento, para então planejar uma pesquisa descritiva.

A pesquisa exploratória costuma envolver o levantamento bibliográfico de dados, gráficos, exemplos e observações, com o objetivo de estreitar com o tema a ser estudado. A junção com a pesquisa descritiva visa aprofundar os conhecimentos sobre o tema, visando a descrição minuciosa e detalhada.

\subsection{QUANTO AOS MEIOS: BIBLIOGRÁFICA E PESQUISA DE CAMPO}

Gil (2002) afirma que a pesquisa bibliográfica é realizada com base em materiais já elaborados, constituídos principalmente de livros e artigos científicos. Para um desenvolvimento com embasamentos ricos em conhecimento, com dados relevantes e atuais, será adotada inicialmente a coleta de dados através da pesquisa bibliográfica. Ainda segundo Gil (2002), a contrapartida deste meio é coletar dados equivocados de fontes secundárias, comprometendo a qualidade da pesquisa. Cabe ao pesquisador certificar-se da procedência dos dados coletados, bem como a sua correta análise.

Zanella (2013) afirma que a principal vantagem do uso do método bibliográfico é permitir ao pesquisador uma cobertura mais ampla do que a utilização de um método de pesquisa direta.

A pesquisa de campo é caracterizada por investigação que pode ser somada a pesquisa bibliográfica sólida e bem fundamentada. $\mathrm{O}$ uso desse meio terá como 
finalidade observar os conceitos e os fatos constatados na pesquisa bibliográfica em sua realidade.

\section{CONSIDERAÇÕES FINAIS}

A pesquisa demonstrou a relevância da adoção de critérios, métodos, técnicas e do controle interno adequado na gestão de estoques das microempresas. Boas ações de controle de estoque e métodos eficientes de gerenciamento de estoques são o principal pilar para manter os mesmos com níveis elevados de confiabilidade da informação contábil. Cabe aos gestores implementar ações e métodos que contribuam diretamente em um controle físico e contábil eficiente.

O assunto abordado é um dos problemas mais enfrentados pelos gestores de empresas que possuem estoque físico, seja empresas de pequeno, médio ou grande porte. As entidades do 2 Setor, que tem como objetivo principal a obtenção do lucro, buscam alcançar tal objetivo da maneira mais adequada possível, diminuindo custos e despesas, bem como também, otimizando seus procedimentos internos, de modo a beneficiar diretamente as atividades da entidade, seja ela de produção, comercialização ou ambas.

Os resultados da pesquisa afirmam que a gestão de estoque é indispensável para as empresas que buscam o constante aperfeiçoamento perante as contínuas mudanças de mercado, possibilitando um correto controle do estoque, evitando desperdícios e prejuízos, contribuindo diretamente para a economia de recursos e ao atendimento ininterrupto às demandas dos clientes.

Tendo em vista que o questionamento levantado como base para nortear esta pesquisa foi: qual a importância da gestão de estoques e quais são os procedimentos adequados para se alcançar uma gestão eficiente? Esta pesquisa evidenciou através da metodologia bibliográfica a relevância do tema abordado, sendo demonstrado alguns dos métodos e técnicas que podem ser empregados no processo de gerenciamento de estoques, assim como a utilização de controles 
internos aumentando a confiabilidade da informação contábil com o objetivo de alcançar os resultados desejáveis pelos gestores e administradores.

A pesquisa evidenciou que o controle interno é uma ferramenta de segurança essencial que assegura um nível aceitável de confiabilidade dos procedimentos desenvolvidos tanto na área administrativa, como na área operacional. A falta de controles eficientes e gerenciamento de estoque podem trazer consequências indesejáveis para os gestores da empresa no âmbito gerencial, impactando diretamente na diminuição dos custos e despesas, e no aumento da lucratividade. É notório a importância do estoque para empresa, bem como a sua correta gestão com controles de fato efetivos, dando sempre aos gestores segurança para as tomadas de decisões.

\section{REFERÊNCIAS}

ATTIE, W. Auditoria: Conceitos e Aplicações. 6. ed. São Paulo: Atlas, 2011.

BECKEDORFF, I. A.; GARCIA, E. Logística. Indaial: Asselvi, 2007.

CARRARO, W. B. W. H. et al. Destaques da Contabilidade Gerencial. 1. ed. Porto Alegre: UFRGS, 2018.

CASTRO, R. P. A. de. Sistema de Controle Interno: uma perspectiva do modelo de gestão pública gerencial. 3. ed. Belo Horizonte: Fórum, 2014.

CHIAVENATO, I. Administração nos novos tempos: os novos horizontes em administração. 3. ed. Barueri, SP: Manole, 2014.

CHIAVENATO, I. Iniciação à Administração Geral. 3. ed. Barueri, SP: Manole, 2009.

CHING, H. Y. Gestão de Estoque na Cadeia de Logística Integrada: Supply Chain. 4. ed. São Paulo: Atlas, 2011. 
CPC. Comitê de Pronunciamentos Contábeis. Estoques. Brasília/DF, 2009. Disponível em: <http://www.cpc.org.br/CPC/DocumentosEmitidos/Pronunciamentos/Pronunciamento? $\mid \mathrm{d}=47>$. Acesso em: 21 de agosto de 2021.

CREPALDI, S. A. Auditoria Contábil Teoria e Prática. São Paulo: Atlas, 2009.

DIAS, M. A. P. Administração de materiais: uma abordagem logística. São Paulo: Atlas, 2010.

GELBCKE, E. R. et al. Manual de Contabilidade Societária: aplicável a todas as sociedades: de acordo com as normas internacionais e do CPC. 3. ed. São Paulo: Atlas, 2018.

GIL, A. de L. et al. Gestão: controle interno, risco e auditoria. 1. ed. São Paulo: Saraiva, 2013.

GRAZIANI, Á. P. Gestão de Estoque e Movimentação de Materiais. Palhoça, SC: UnisulVirtual, 2013.

IUDÍCIBUS, S. de. Contabilidade Gerencial. 6. ed. São Paulo: Atlas, 2010.

KNECHTEL, M. do R. Metodologia da pesquisa em educação: uma abordagem teórico-prática dialogada. Curitiba: Intersaberes, 2014.

LOUREIRO, D. P. B. A importância dos controles internos nas organizações. Repositório Digital UFRGS, Porto Alegre, 2010. Disponível em: $<$ https://www.lume.ufrgs.br/bitstream/handle/10183/27239/000763044.pdf?sequence $=1>$. Acesso em: 27 de agosto de 2021 .

LUNKES, R. J. Controle de gestão: estratégico, tático, operacional, interno e de risco. São Paulo: Atlas, 2010. 
LUZ, É. E. da (Org.). Auditoria e perícia contábil trabalhista. São Paulo: Pearson Education do Brasil, 2015.

MARCONI, M. de A.; LAKATOS, E. M. Fundamentos de Metodologia Científica. 8. ed. São Paulo: Atlas, 2017.

MARION, J. C. Contabilidade Empresarial. 17 ed. São Paulo, SP: Atlas, 2015.

MARTINS, P. G.; ALT, P. R. C. Administração de Materiais e Recursos Patrimoniais. 3. ed. São Paulo: Saraiva, 2009.

MARTINS, P. G.; ALT, P. R. C. Administração de materiais e recursos patrimoniais. 5. ed. São Paulo: Saraiva, 2010.

NASCIMENTO, A. M. et al. Sistemas de Controles Internos. In: NASCIMENTO, A. M.; REGINATO, L. (Org.). Controladoria: um enfoque na eficácia organizacional. 2. ed. São Paulo: Atlas, 2009.

NOVAES, A. G. Logística e gerenciamento da cadeia de distribuição. Rio de Janeiro: Campus, 2010.

PADOVEZE, C. L. Contabilidade Gerencial. Curitiba: IESDE, 2012

PEREIRA, A. S. et al. Metodologia da Pesquisa Científica. 1. ed. Santa Maria, RS: UFSM, NTE, 2018.

PINTO, R. da S. et al. A importância do gerenciamento de estoque nas micro e pequenas empresas de materiais de construção de São Gonçalo. Revista de Trabalhos Acadêmicos-Campus Niterói, 2017. Disponível em: $<$ http://www.revista.universo.edu.br/index.php?journal=1 reta2\&page=article\&op=view \&path\%5B\%5D=3747\&path\%5B\%5D=2404 >. Acesso em: 29 de agosto de 2021.

RIBEIRO, O. M. COELHO, J. M. R. Auditoria Fácil. 2. ed. São Paulo: Saraiva, 2013. 
RIBEIRO, O. M. Contabilidade Geral Fácil. 9. ed. São Paulo: Saraiva, 2013.

RIBEIRO, O. M. Contabilidade Intermediária. 2. ed. São Paulo: Saraiva, 2009.

SANTOS, M. dos.; TRINDADE, L. de L. A contribuição dos controles internos para a eficácia e eficiência da gestão operacional: um estudo de caso. Disponível<file:///C:/Users/Ten\%20Lima/Downloads/11194-40941-1-PB.pdf>. Acesso em 20 agosto de 2021.

SCHIER, C. U. da C. Gestão de custos. 2 ed. Curitiba, PR: Ibpex, 2011.

SILVA, F. C. da. O controle Interno nas Pequenas e Médias Empresas. Biblioteca da Faculdade Cearense, Fortaleza, 2013. Disponível em: $<$ https://www.faculdadescearenses.edu.br/biblioteca/TCC/CCO/CONTROLE\%20INT ERNO\%20NAS\%20PEQUENAS\%20E\%20MEDIAS\%20EMPRESAS.pdf>. Acesso em 28 de agosto de 2021.

SOUSA, D. $O$ que você precisa saber sobre Estoque Físico $X$ Estoque Contábil. Softecsul Inovação, 2020. Disponível em: <https://www.softecsul.digital/post/o-quevoc\%C3\%AA-precisa-saber-sobre-estoque-f\%C3\%Adsico-x-estoquecont\%C3\%A1bil>. Acesso em: 17 de março de 2021.

TORRES, V. Microempresa: O que é uma ME? Como funciona, definição e características. Contabilizei.blog, 2021. Disponível em: $<$ https://www.contabilizei.com.br/contabilidade-online/o-que-e-microempresa-e-quala-diferenca-com-outros-tipos/>. Acesso em: 29 de agosto de 2021.

VAASSEN, E. et al. Controle interno e sistemas de informação contábil. São Paulo: Saraiva, 2013.

WARREN, C. S. et al. Fundamentos de Contabilidade: Aplicações. 22. ed. São Paulo: Cengage Learning, 2009. 
ZANELLA, L. C. H. Metodologia de pesquisa. 2. ed. reimp. Florianópolis: Departamento de Ciências da Administração/UFSC, 2013.

Enviado: Outubro, 2021.

Aprovado: Novembro, 2021. 